\title{
METODOLOGIA DE ENSINO JIGSAW EM DISCIPLINA DE QUÍMICA MEDICINAL
}

\author{
Luciana Massi, Bianca Machado Cerrutti e Salete Linhares Queiroz* \\ Instituto de Química de São Carlos, Universidade de São Paulo, CP 780, 13560-970 São Carlos - SP, Brasil
}

Recebido em 8/10/12; aceito em 5/12/12; publicado na web em 12/3/13

\begin{abstract}
THE JIGSAW METHOD ON A MEDICINAL CHEMISTRY COURSE. In this paper, we describe an educational experience involving the use of the jigsaw method on the Medicinal Chemistry course at the University of São Paulo, Brazil. The goal of this proposal was to investigate acceptance and contributions of the method to undergraduate chemistry teaching. Feedback on the jigsaw method collected from the focus groups and questionnaires showed that participants generally acknowledged the advantages of the jigsaw method in helping them learn the Medicinal Chemistry subject. Suggestions for improving the jigsaw method were also received from participants.
\end{abstract}

Keywords: Medicinal Chemistry; didactic tool; higher education.

\section{INTRODUÇÃO}

Recursos humanos para atuação na Química Medicinal representam um desafio de formação multidisciplinar para farmacêuticos, químicos orgânicos, químicos medicinais teóricos, biólogos, biólogos moleculares, químicos biofísicos, entre outros. ${ }^{1}$ No Brasil, a falta de qualificação profissional, incentivos e políticas de formação de recursos humanos nessa área é destacada por Barreiro ${ }^{2}$ como um dos fatores que impedem seu desenvolvimento. Nesse mesmo sentido, podemos inferir, a partir do trabalho de Lima, ${ }^{3}$ que esse quadro pode contribuir para a situação atual de contribuição nacional ainda tímida, em termos numéricos, para a produção de conhecimentos novos na área de Química Medicinal.

O enfrentamento desse desafio passa diretamente pela questão de uma formação interdisciplinar que atenda às demandas do mercado de trabalho. Esses são os princípios da estrutura curricular do curso de graduação em Ciências Físicas e Biomoleculares, oferecido pelo Instituto de Física de São Carlos, da Universidade de São Paulo (IFSC/USP). Criado em 2006 e sendo o primeiro da América Latina, o curso tem como base a abordagem molecular dos fenômenos biológicos. ${ }^{4}$ Dentre as diversas disciplinas oferecidas existe um enfoque na Química Medicinal, abordada em profundidade crescente ao longo dos semestres de graduação.

Nesse contexto, discutimos neste trabalho o ensino da Química Medicinal diante de desafios novos, envolvendo a interdisciplinaridade, e antigos, relacionados à busca por estratégias didáticas que promovam o interesse dos alunos e desenvolvam habilidades relevantes para a sua formação. De fato, encontramos pesquisas internacionais ${ }^{5-7}$ e nacionais ${ }^{8,9}$ sobre o ensino dessa disciplina em cursos de Farmácia que destacam a necessidade de estratégias que fomentem a articulação necessária entre os diferentes campos de conhecimento envolvidos na Química Medicinal.

Considerando esses resultados e as necessidades formativas do referido curso de graduação, elaboramos a proposta de ensino descrita neste trabalho, pautada na utilização de textos publicados na revista Química Nova e na metodologia jigsaw. Como ressaltado por Lima, ${ }^{3}$ existe uma publicação principal sobre Química Medicinal em língua portuguesa, ${ }^{10}$ o que nos levou a procurar outros textos em português e de fácil entendimento para abordar o tema. Essa busca nos levou à extinta seção de Divulgação da revista Química Nova, que apresenta particularidades em relação aos textos tradicionalmente

*e-mail: salete@iqsc.usp.br categorizados como de divulgação. Segundo Oliveira e Queiroz, ${ }^{11}$ os artigos nela publicados apresentam assuntos relacionados a alguma área de ciência e são redigidos de forma distinta dos artigos originais de pesquisa: o assunto é direcionado a um público especializado em Química, embora o autor se preocupe em conceituar termos técnicos.

Em nossa proposta selecionamos diferentes artigos sobre o tema "Química Medicinal" e solicitamos aos alunos de graduação que os estudassem e produzissem um texto no qual fossem estabelecidas, com a maior plenitude possível, relações entre os mesmos. A partir de uma definição prévia das relações existentes entre os artigos, verificamos a sua presença nos textos produzidos pelos alunos. O que nos permitiu a tessitura de considerações sobre a estratégia aplicada e a capacidade dos alunos de estabelecerem relações entre diferentes conceitos de um mesmo campo, através do trabalho em grupo. Acreditamos que o estabelecimento, por parte dos alunos, de relações entre os textos aos quais nos remetemos indicaria um trabalho efetivo de compreensão e análise do texto original na produção textual.

Com a aplicação da proposta, esperávamos que a leitura e a discussão dos artigos, por seu caráter interdisciplinar, favorecessem o entendimento dos alunos com relação à aplicação dos conceitos de Química Orgânica nas pesquisas realizadas na área de Química Medicinal, complementando e fortalecendo a compreensão dos conteúdos específicos da disciplina.

\section{ARTIGOS SELECIONADOS E RELAÇÕES EXISTENTES ENTRE ELES}

A Tabela 1 apresenta as referências completas dos artigos selecionados para utilização na proposta de ensino, cabendo ainda destacar que estes foram também avaliados e aprovados pelo docente responsável pela disciplina. Considerando todo o conjunto de artigos publicados na seção Divulgação da revista Química Nova, sem alimentação a partir de 2008, não encontramos textos mais recentes com as características desejadas.

O artigo 1, "Química Medicinal: contribuição e perspectiva no desenvolvimento da farmacoterapia", de Montanari, ${ }^{1}$ trata da síntese de compostos orgânicos com atividade biológica e do estudo das relações entre estrutura química e atividade biológica, SAR/ QSAR. Montanari ${ }^{1}$ apresenta avanços importantes na evolução dos medicamentos, como: uso de medicamentos derivados de plantas; isolamento de produtos naturais de plantas e animais; rápido crescimento dos produtos sintéticos; modificação da estrutura de produtos naturais. Destaca que o Brasil se encontra em estágio inferior no 
Tabela 1. Relação de artigos adotados na proposta de ensino

Título dos artigos e nome dos autores

Revista, volume, número, página, ano.

1 Montanari, C. A. Química Medicinal: contribuição e perspectiva no desenvolvimento da farmacoterapia.

Química Nova, v. 18, n. 1, p. 56, 1995.

2 Barreiro, E. J. Produtos naturais bioativos de origem vegetal e o desenvolvimento de fármacos.

Química Nova, v. 13, n. 1, p. 29, 1990.

3 Barreiro, E. J. A importância da síntese de fármacos na produção de medicamentos.

Química Nova, v. 14, n. 3, p. 179, 1991.

4 Barreiro, E. J. Substâncias enantiomericamente puras (SEP): a questão dos fármacos quirais.

Química Nova, v. 20, n. 6, p. 647, 1997.

que se refere à busca, síntese de produtos naturais e modificação de moléculas obtidas de produtos naturais. Ressalta que a descoberta de uma nova substância não significa contribuição efetiva para inovação ou descoberta de um novo fármaco. Portanto, segundo o autor, em Química Medicinal é preciso trabalhar em duas frentes: produzir novas substâncias e dominar a tecnologia necessária para produzir medicamentos. Acrescenta ainda que no Brasil a produção de novas substâncias é restrita à pesquisa universitária e que subsidiárias de multinacionais desenvolvem apenas as etapas finais dos processos de obtenção de novos medicamentos, os intermediários são importados das matrizes (dados de 1995). Basicamente, então, a Química Medicinal envolve o isolamento ou a síntese de compostos com atividade biológica, elucidação de estruturas, caracterização de propriedades físico-químicas e SAR/QSAR. Essa complexidade exige trabalho multidisciplinar e pessoas qualificadas atuando em conjunto.

$\mathrm{O}$ artigo 2, "Produtos naturais bioativos de origem vegetal e o desenvolvimento de fármacos", de Barreiro, ${ }^{2}$ apresenta aspectos sobre o papel das substâncias naturais bioativas como protótipos para o desenvolvimento de novos fármacos. Segundo o autor, o homem se utiliza de substâncias naturais de plantas para curar doenças há muito tempo, mas com a possibilidade de síntese de novos compostos com potencial farmacológico, o interesse por substâncias naturais bioativas, cresceu consideravelmente. Barreiro ${ }^{2}$ apresenta e discute os cardiotônicos (substâncias tonificantes do músculo cardíaco), os alcaloides (com propriedades analgésicas e antimaláricas), o curare (poderoso bloqueador neurotransmissor), além de substâncias naturais de origem vegetal com ação anticâncer. Afirma que diversos grupos de pesquisa estudam atividade biológica de famílias de substâncias naturais, com base em modificações moleculares, que permitem o desenvolvimento de medicamentos sintéticos mais seguros, originados do protótipo natural. Concluindo seu artigo, ressalta que a viabilidade do emprego de substâncias naturais em Medicina depende muito da interação entre pesquisadores de diversas áreas, principalmente o químico e o farmacologista, devido ao caráter polidisciplinar da Química Medicinal, que já havia sido mencionado no artigo 1.

O artigo 3, "A importância da síntese de fármacos na produção de medicamentos", de Barreiro, ${ }^{12}$ discute razões pelas quais a síntese de fármacos ocupa importante papel na indústria farmacêutica e compara a síntese de fármacos no Brasil com mercados mais avançados. Segundo o autor, um dos desdobramentos da Química Orgânica é a síntese de fármacos, capaz de produzir substâncias de elevado grau de pureza, em escala minimolar, até escalas multimolares. Considerando que essa síntese é um processo de várias etapas, o produto depende da rota sintética, do grau de pureza dos intermediários e das matérias-primas. A metodologia deve ser escolhida no sentido de obter elevado rendimento, com menor custo e elevada pureza. Disso depende a segurança do futuro medicamento. $\mathrm{O}$ autor ainda afirma que o mercado mundial de produtos farmacêuticos supera $116 \mathrm{mi}$ lhões de dólares anuais, desse total o Brasil participa com 2 milhões de dólares, correspondendo a $18 \%$ do mercado mundial (dados de 1982). Ademais, destaca que o consumo per capita de medicamentos no Brasil é de 14 dólares, um valor inferior a países de primeiro mundo. Esse dado poderia sugerir que a saúde do brasileiro é superior à da população dos países desenvolvidos, porém, considerando-se que a medicina preventiva é minoritária no Brasil, percebe-se que o acesso da população aos medicamentos é limitado. $\mathrm{O}$ artigo discute a relação entre a produção de medicamentos sintéticos e o mercado farmacêutico, ressaltando que o valor agregado ao medicamento chega a corresponder a 17 vezes o custo da matéria-prima, devido aos gastos com as pesquisas e produção. Barreiro ${ }^{12}$ comenta ainda sobre a falta de qualificação profissional, incentivos e políticas de formação de recursos humanos nessa área no Brasil, apesar da nossa abundância de matérias-primas.

$\mathrm{O}$ artigo 4, "Substâncias enantiomericamente puras (SEP): a questão dos fármacos quirais", também de Barreiro, ${ }^{13}$ apresenta uma visão geral sobre a importância da quiralidade nos compostos orgânicos e sua relação com a atividade biológica. Segundo o autor, existe imenso interesse, na comunidade científica e no setor industrial, em substâncias enantiomericamente puras (SEP). A origem dessa demanda está ligada a estudos que relacionam propriedades biológicas com quiralidade molecular. Apresenta os conceitos de quiralidade, enantiômeros, diastereômeros e sua interação biológica, exemplificando com o caso da talidomida. O medicamento era indicado para enjoos de gestantes, mas causou má formação nos fetos. Descobriu-se que ele foi vendido na forma de uma mistura racêmica biologicamente ativa, na qual o isômero $(\mathrm{R})$ tinha propriedades sedativas, hipnóticas, enquanto que o isômero (S) possuía propriedades teratogênicas. Atualmente, os países mais atuantes na indústria farmacêutica estabeleceram novos protocolos relacionados à mistura racêmica para a liberação de uma nova droga, aumentando o custo e o tempo até essa chegar ao Mercado. Segundo Barreiro, ${ }^{13}$ a situação do mercado farmacêutico no Brasil se resume ao domínio das multinacionais, o que traz consequências como a falta de medicamentos para a população. Companhias farmacêuticas terceirizam o processo de resolução de drogas quirais, devido a seu alto custo e tempo. Empresas especializadas em produtos quirais têm oferecido vantagens à indústria farmacêutica, sendo as únicas limitações, o custo de alguns procedimentos e a não disponibilidade de algumas matérias-primas. O autor conclui apresentando a preparação de substâncias enantiomericamente puras como um desafio para a Química Orgânica e discutindo quais etapas devem ser controladas nesses processos.

Como podemos perceber a partir dos resumos, os artigos abordam aspectos diferentes da Química Medicinal. O artigo 1 enfoca a relação entre estrutura e atividade biológica (SAR/QSAR) e a posição do Brasil em relação à pesquisa e produção de medicamentos naturais, o artigo 2 destaca o potencial farmacológico de substâncias naturais e exemplifica substâncias que agem contra doenças como malária e câncer, o artigo 3 apresenta um panorama econômico sobre a síntese de fármacos e indústrias farmacêuticas no Brasil e no mundo, e, finalmente, o artigo 4 discute a relação entre as substâncias enantioméricas e a síntese de fármacos. Apesar de enfocarem aspectos diferentes, existem temas que são recorrentes em todos os textos como, por exemplo, síntese de fármacos abordada em diferentes perspectivas; relação entre estrutura química e atividade biológica; contexto nacional e internacional de pesquisa e mercadológico; aspectos sobre a formação de recursos humanos para a área de Química Medicinal. A partir dessa análise do conteúdo dos artigos elaboramos a rede de relações ilustrada na Figura 1, que foi utilizada como referência para 
avaliação dos trabalhos redigidos pelos alunos sobre esses mesmos textos, segundo as considerações presentes no Quadro 1.

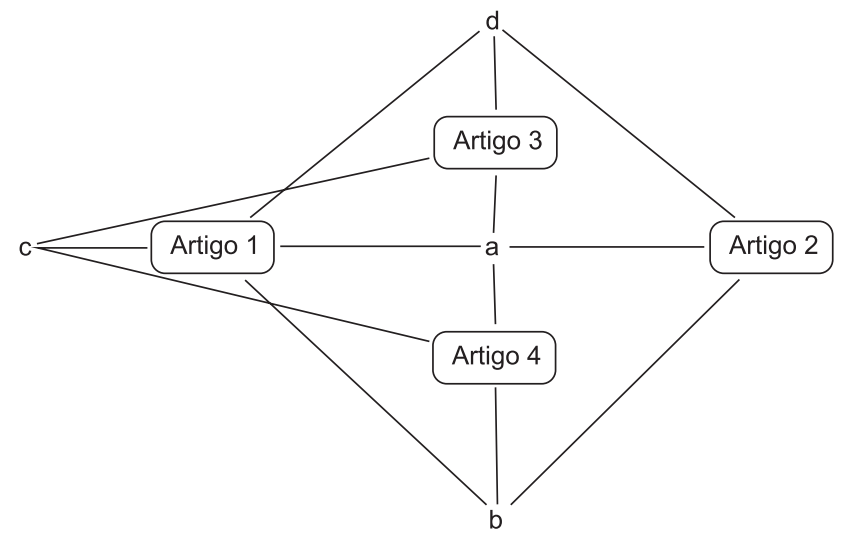

Figura 1. Rede de relações presentes nos artigos

Quadro 1. Relações entre os artigos propostos no estudo

\begin{tabular}{|cl|}
\hline Relação & Possibilidade de relações a serem trabalhadas \\
\hline a & $\begin{array}{l}\text { Os quatro artigos abordam aspectos da síntese de fármacos. } \\
\text { Porém o artigo } 1 \text { discute a evolução e etapas dos processos de } \\
\text { síntese. O artigo } 2 \text { discute a síntese a partir de produtos naturais. } \\
\text { O artigo } 3 \text { trabalha com a síntese de fármacos sintéticos e o } \\
\text { artigo } 4 \text { discute as implicações da quiralidade nos processos } \\
\text { de síntese. }\end{array}$ \\
\hline b & $\begin{array}{l}\text { Os artigos 1, } 2 \text { e } 4 \text { discutem a relação entre estrutura química } \\
\text { e atividade biológica. No artigo } 1 \text { a discussão é detalhada, en- } \\
\text { volvendo aspectos históricos e conceituais sobre SAR/QSAR; } \\
\text { no artigo } 2 \text { novamente abordam-se alguns aspectos históricos, } \\
\text { apresentam-se as relações entre as classes de produtos naturais } \\
\text { e a atividade biológica e discute-se o exemplo dessa relação } \\
\text { na substância curare; no artigo } 4 \text { a discussão sobre a relação } \\
\text { estrutura e atividade está relacionada à quiralidade. }\end{array}$ \\
\hline c & $\begin{array}{l}\text { Os artigos 1, } 3 \text { e } 4 \text { discutem os contextos nacionais e interna- } \\
\text { cionais da síntese de fármacos. No artigo } 1 \text { foca-se o contexto } \\
\text { das pesquisas e indústrias e nos artigos } 3 \text { e } 4 \text { abordam-se os } \\
\text { aspectos mercadológicos envolvidos na síntese de fármacos. }\end{array}$ \\
\hline d & $\begin{array}{l}\text { Os artigos 1, } 2 \text { e } 3 \text { discutem a questão da formação de recursos } \\
\text { humanos para a área de Química Medicinal. Os artigos } 1 \text { e } 2 \\
\text { destacam a importância de equipes multidisciplinares e o artigo } \\
\text { 3 trabalha a questão da formação de pessoas na pós-graduação } \\
\text { e no contexto universitário. }\end{array}$ \\
\hline
\end{tabular}

\section{ELABORAÇÃO DA PROPOSTA DE ENSINO}

A elaboração da proposta de ensino envolveu a participação de 8 alunos do Programa de Pós-Graduação do Instituto de Química de São Carlos (IQSC/USP), estagiários do Programa de Aperfeiçoamento de Ensino (PAE) ${ }^{14}$ da Universidade de São Paulo, dentre os quais as 2 primeiras autoras deste manuscrito. Pesquisa recente, publicada nesta revista, ${ }_{15}^{15}$ aponta para as contribuições desse Programa para a formação docente no contexto das disciplinas Comunicação e Expressão em Linguagem Científica I, do curso de Bacharelado em Química do IQSC/ USP e Laboratório de Química Geral, do curso de Bacharelado em Ciências Físicas e Biomoleculares do IFSC/USP. Dentre as exigências do Programa PAE do IQSC, além da atuação dos pós-graduandos junto às disciplinas selecionadas para realização do estágio, estes participam também de reuniões coordenadas por um docente do IQSC/USP. Nas reuniões são solicitados a elaborar em grupo e, eventualmente, aplicar uma proposta de ensino referente a uma disciplina escolhida pelos componentes do grupo. Dessa forma originou-se a proposta aqui descrita.
A disciplina selecionada pelos estagiários foi a SQM0455Química Medicinal, oferecida no Curso de Bacharelado em Ciências Físicas e Biomoleculares. No momento da aplicação da proposta didática, a disciplina em questão (teórica, 6 créditos) era ministrada no $2^{\circ}$ semestre do Curso e abarcava os seguintes objetivos: proporcionar ao estudante conhecimentos sobre conceitos básicos de Química Orgânica, de modo a torná-lo apto a relacioná-los com a natureza da estrutura química e suas propriedades biológicas, físicas e químicas; apresentar os fundamentos da Química Orgânica de moléculas de interesse biológico, com ênfase nos estudos da estrutura, mecanismo de reação, grupos funcionais, reatividade e estereoquímica; explorar os fundamentos básicos de Química Medicinal.

De acordo com a grade curricular vigente no momento da aplicação desta proposta, a disciplina era ministrada após a disciplina SQF0318-Introdução à Química, e proporcionava o segundo contato dos alunos com os conteúdos de Química, no nível superior. Uma vez que os princípios básicos da Química Orgânica não haviam ainda sido estudados neste nível de ensino, grande parte dos conteúdos ministrados na disciplina dizia respeito a esses princípios e não aos fundamentos de Química Medicinal, como o nome da disciplina sugere. Foi levando em consideração esse contexto e a crença de que as atividades realizadas com os artigos de divulgação científica poderiam suscitar o interesse dos alunos e o maior conhecimento sobre aspectos relevantes da Química Medicinal, entre outros benefícios, que a proposta foi elaborada.

Optamos por adotar os 4 artigos, publicados na seção Divulgação (Tabela 1), tendo em vista as seguintes características, consideradas favoráveis ao contexto de aplicação da proposta: são redigidos em língua portuguesa, trazem aspectos gerais dos trabalhos realizados pelos cientistas e empregam uma linguagem acessível ao leitor iniciante na área de Química. Discussões levadas a cabo pelos estagiários PAE apontaram para a inadequação da utilização, na disciplina em questão, de artigos que reportassem resultados originais de pesquisas. Estes foram considerados muito complexos, uma vez que os alunos só haviam concluído uma disciplina da área.

\section{ETAPAS DE APLICAÇÃO DA PROPOSTA DE ENSINO}

A primeira etapa de aplicação da proposta teve início no $2^{\circ}$ bimestre letivo, no qual ocorreu a apresentação e a explicação das atividades que a constituíam aos alunos. Nesta ocasião, a classe, composta por 23 alunos, foi dividida em 4 grupos, e a cada grupo foi atribuída a tarefa de responder questões sobre os conteúdos apresentados em cada um dos artigos selecionados. Essas questões foram divididas em questões comuns a todos os artigos e questões específicas, relacionadas ao conteúdo de cada artigo. As questões gerais e as questões específicas, relacionadas a cada um dos artigos, se encontram ilustradas nos Quadros 2 e 3, respectivamente, e foram elaboradas com o intuito de facilitar a sua leitura e interpretação.

Quadro 2. Questões gerais relacionadas aos artigos

1. Durante a leitura do artigo sublinhe todas as palavras/expressões cujo significado não é conhecido e, em seguida, elabore um glossário.

2. Selecione 3 estruturas químicas no texto e identifique suas respectivas classes terapêuticas (sugestão: consultar o site da Agência Nacional de Vigilância Sanitária - Anvisa).

3. Identifique 5 grupos funcionais diferentes nas estruturas dos compostos orgânicos apresentadas no artigo.

Em seguida, os grupos tinham ainda a incumbência de elaborar um resumo do assunto discutido no artigo. Para tanto, deveriam 
Quadro 3. Questões específicas relacionadas aos artigos

\begin{tabular}{|c|c|}
\hline Artigo 1 & $\begin{array}{l}\text { 6. Diferencie interações biológicas específicas e não específicas. } \\
\text { 7. Cite três métodos físicos empregados na caracterização da estru- } \\
\text { tura química. } \\
\text { 8. Qual a importância da síntese de enantiômeros puros? Cite } \\
\text { exemplos do artigo. } \\
\text { 9. De acordo com o texto, qual o papel da síntese orgânica na produção } \\
\text { de novos medicamentos? } \\
\text { 10. Como os produtos naturais são utilizados no desenvolvimento } \\
\text { de fármacos? }\end{array}$ \\
\hline Artigo 2 & $\begin{array}{l}\text { 4. Dentro do conceito do reconhecimento de padrão molecular, } \\
\text { identifique o grupo comum entre as estruturas das 4-fenilpiperidinas } \\
\text { (estruturas } 6,7 \text { e } 8 \text { ). } \\
\text { 5. Mostre as equações de hidrólise ácida da atropina com seus res- } \\
\text { pectivos produtos de reação. } \\
\text { 6. Apresente quatro estruturas, ressaltando a quais classes químicas } \\
\text { pertencem, com atividade anticâncer. } \\
\text { 7. Identifique o esqueleto estrutural base das quinonas e terpenos. } \\
\text { 8. Substâncias químicas de uma mesma classe terapêutica possuem } \\
\text { mesma atividade biológica? Justifique. } \\
\text { 9. Como seria possível converter a vimblastina à vincristina em } \\
\text { laboratório? } \\
\text { 10. Como você justificaria a importância dos produtos naturais } \\
\text { no desenvolvimento de fármacos, se apenas } 11,5 \% \text { dos fármacos } \\
\text { utilizados na década de } 90 \text { são produtos naturais, segundo o artigo. }\end{array}$ \\
\hline Artigo 3 & $\begin{array}{l}\text { 4. Qual o gasto dos brasileiros com produtos farmacêuticos? O que } \\
\text { isso acarreta para a saúde da população brasileira? } \\
\text { 5. O que justifica a elevada margem de lucro da indústria farmacêu- } \\
\text { tica? } \\
\text { 6. Como a síntese química pode agregar valor ao produto farmacêu- } \\
\text { tico? Utilize os exemplos das duas substâncias analgésicas citadas } \\
\text { no artigo (AAS e paracetamol). } \\
\text { 7. Por que determinado fármaco obtido em laboratório pode não ser } \\
\text { viável para produção industrial? } \\
\text { 8. De que maneira a indústria farmacêutica americana atrai pesqui- } \\
\text { sadores qualificados (pós-graduados) para esse setor? } \\
\text { 9. Faça um paralelo entre a indústria farmacêutica no exterior e no } \\
\text { Brasil quanto à qualificação profissional. } \\
\text { 10. Por que atualmente são tão importantes as pesquisas de quali- } \\
\text { dade nesse setor e o que deve ser feito para melhorar a indústria } \\
\text { farmacêutica brasileira? }\end{array}$ \\
\hline Artigo 4 & $\begin{array}{l}\text { 4. Sobre as substâncias enantiomericamente puras (SEP), responda: } \\
\text { a) O que são SEP? } \\
\text { b) Identifique os átomos de carbono quiral presentes nas estru- } \\
\text { turas apresentadas nas Figuras } 1 \text { e } 2 \text { e na Tabela } 3 \text {. } \\
\text { c) Identifique as estruturas R e S do ácido lático (Figura 1). } \\
\text { Justifique. } \\
\text { 5. Quais são as implicações da quiralidade na produção de medi- } \\
\text { camentos? } \\
\text { 6. A Figura 6, (R - Epinefrina), faz referências a sítio aniônico, } \\
\text { receptor de ponte de hidrogênio e receptor de área plana. Comente o } \\
\text { tipo de interação que representam. } \\
\text { 7. Quais são as semelhanças e diferenças entre dois pares de enanti- } \\
\text { ômeros? Cite exemplos. } \\
\text { 8. O que significam reações estereosseletivas? Cite ao menos } 2 \\
\text { exemplos. } \\
\text { 9. Misturas racêmicas podem ser usadas como substâncias ativas de } \\
\text { medicamentos? Justifique. } \\
\text { 10.Quais são as técnicas de separação de racematos e síntese assi- } \\
\text { métrica para obtenção de SEP? Você acredita que os pesquisadores } \\
\text { prefiram obter SEP diretamente na síntese ou por meio da separação } \\
\text { de racematos? }\end{array}$ \\
\hline
\end{tabular}

procurar seguir as seguintes "Diretrizes para Elaboração do Resumo", que são semelhantes às sugeridas por Paulson ${ }^{16}$ em trabalho realizado em disciplina especificamente voltada para a familiarização dos estudantes com a linguagem científica:

1. Enquanto você lê cada parágrafo, escreva uma frase resumindo o parágrafo em questão. Faça o mesmo com todos eles.

2. Ao término da leitura, elabore uma única frase resumindo a ideia principal do texto.

3. Com base nas frases que você escreveu para cada parágrafo produza um texto coeso que sintetize todo o conteúdo do artigo. Este resumo deverá conter no mínimo 2500 caracteres.

A apresentação da proposta e as orientações dadas pelos estagiários PAE aos alunos quanto à realização das tarefas não ultrapassaram 20 min, não prejudicando, portanto, o andamento normal da aula do professor da disciplina. Ficou estipulado o prazo de 1 mês para a entrega das resoluções para as questões e dos resumos.

Na segunda etapa de aplicação da proposta os estagiários PAE retornaram à sala de aula, recolheram as tarefas solicitadas anteriormente e coordenaram discussões sobre os conteúdos dos artigos. Como estratégia para propiciar a interação entre os alunos em uma discussão em que todos estivessem envolvidos, foi adotado o trabalho em grupo no formato jigsaw, ${ }^{17,18}$ desenvolvido de forma invertida em relação ao padrão tradicional. Em nossa aplicação do método, inicialmente foi realizada a divisão dos alunos em diferentes grupos de especialistas, de maneira que cada um dos grupos estudasse e discutisse apenas uma parte do material didático. Nesse caso, o material era o artigo que cada grupo recebeu e sobre o qual deveria responder o questionário e elaborar um resumo, portanto, esta etapa foi realizada extraclasse durante 1 mês.

Em um segundo momento, que em nossa proposta equivale à etapa final de aplicação da estratégia, conduzida em aula pelos estagiários, foram formados novos grupos (grupos de base) com um representante de cada grupo de especialistas da formação anterior, criando-se grupos de base mistos, nos quais cada componente teria conhecimento sobre uma parte do material acadêmico, ou seja, cada componente seria "responsável" por um artigo que teria lido, resolvido exercícios e feito um resumo junto com o seu grupo de especialistas. Considerando que na proposta existia a necessidade de que cada grupo de base tivesse pelo menos um representante de cada artigo, ou seja, de cada grupo de especialistas que continha 4 membros, foram formados 4 novos grupos na etapa final. Assim, o grupo de base realizou uma discussão na qual cada aluno apresentou considerações sobre sua parte aos outros membros. $\mathrm{O}$ objetivo desses grupos de base ("mistos") era a elaboração de uma redação com o título "Química Medicinal" na qual os alunos procurariam relacionar o conteúdo dos 4 artigos, através da colaboração de todos os integrantes do grupo. Ao término da atividade, esperava-se que todos tivessem compreendido o conteúdo completo do material acadêmico proposto, ou seja, todos conhecessem o teor dos 4 artigos sobre Química Medicinal. Um diagrama esquemático do método de jigsaw adaptado à nossa situação de ensino é apresentado na Figura 2.

O objetivo dessa atividade era verificar até que ponto os alunos conseguiriam efetivamente trabalhar com conteúdos dos 4 artigos, mesmo tendo lido e trabalhado mais detidamente apenas com um deles. Assim, considerando a rede de relações que elaboramos para os textos e apresentamos na Figura 1 e Quadro 1, procuramos, nas redações elaboradas pelos alunos, indícios de relações e entrecruzamentos entre os conteúdos abordados nos artigos. Com isso procuramos tecer considerações tanto sobre a metodologia proposta quanto sobre a aprendizagem dos alunos a respeito da Química Medicinal, entendida aqui como a capacidade de enxergar e estabelecer relações entre conceitos. 


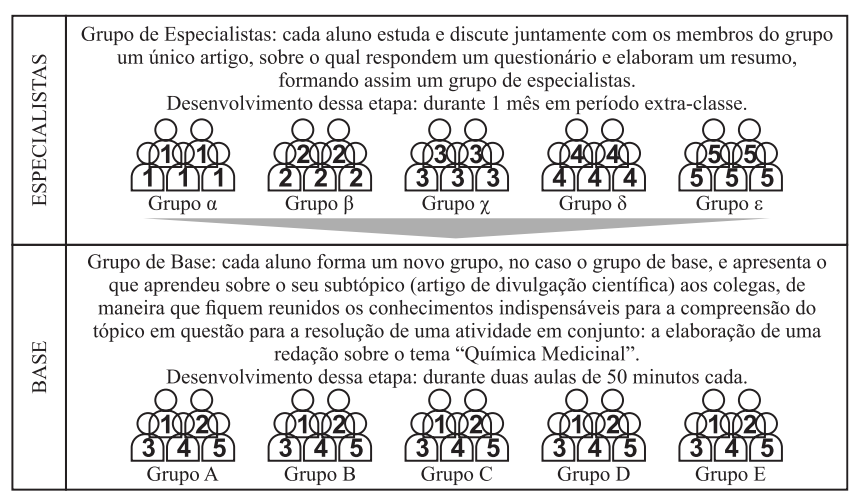

Figura 2. Diagrama do método jigsaw ${ }^{18}$

\section{REDE DE RELAÇÕES ENTRE OS TEXTOS NA PERSPECTIVA DOS ALUNOS}

A redação elaborada pelos alunos nos grupos de base foi considerada o produto final da atividade didática, portanto não discutiremos aqui os resultados apresentados pelos alunos na etapa de resolução dos questionários e elaboração dos resumos nos grupos de especialistas. Nesse sentido analisaremos cada uma das redações destacando a presença dos temas a, b, c e d conforme definidos no Quadro 1.

\section{Um panorama sobre Química Medicinal}

A redação intitulada "Um Panorama Sobre Química Medicinal”, abordou os temas a, b e c. No primeiro [1] e segundo parágrafos [2] há um enfoque na síntese de fármacos, tema a, no qual os alunos descrevem as etapas, desenvolvimento e planejamento da síntese, apresentando o conceito de Química Medicinal. Destacamos que embora o tema estivesse presente em todos os artigos, nessa redação privilegiaram-se os conteúdos do artigo 1, embora tenhamos percebido elementos dos demais.

[1] "A obtenção de um novo fármaco não é um processo trivial. Consiste-se de uma gama de processos de planejamento e desenvolvimento que acarretam uma considerável demanda de tempo e dinheiro"

[2] "Este processo inicia-se com uma gênese planejada de fármacos, na qual estão inseridas as etapas de...”

No terceiro parágrafo [3] os alunos transcreveram uma frase do artigo 1 , confirmando a sua predominância no momento de escrita do texto.

[3] “A Química Medicinal trouxe consigo uma diferenciação em todos esses processos na obtenção de fármacos..."

No quarto [4] e quinto [5] parágrafos os alunos discutem a relação estrutura-atividade, ou seja, o que definimos como tema b no Quadro 1. Nesses trechos ainda percebemos elementos do artigo 1, embora descritos de forma livre e diferente do que aparecia no texto original. Notamos também a incorporação de temas do artigo 4, a questão da quiralidade.

[4] "estudo da estrutura molecular que está associada à doença e determinar esta estrutura; então, desenvolve-se a molécula orgânica que vai agir no sítio ativo dessa estrutura [...] neste tópico é importante citar que muitas destas moléculas orgânicas são enantioméricas, contudo, em algumas delas só um dos compostos enantiômeros é ativo no sistema biológico"
[5] "com a molécula pronta, passa-se para os testes in vitro e vencida esta etapa, passam-se aos estudos farmacocinéticos, farmacodinâmicos...”

No sexto [6] e sétimo [7] parágrafos ocorre a discussão de outro tema presente nos artigos, os aspectos mercadológicos, que consideramos como tema c. No sexto parágrafo há um enfoque nos conteúdos do artigo 3 e no sétimo parágrafo privilegia-se o artigo 1 .

[6] "Todos esses processos envolvem muitos estudos, e muitos investimentos, que provém de particulares [...] podendo um remédio chegar a dezessete vezes mais caro do que seu custo de produção"

[7] "o desenvolvimento de fármacos é um processo tão complexo e que por isso fica restrito aos países com melhores condições"

Apesar de abordar diferentes temas e enfocar diferentes artigos em cada momento do texto, destacamos que a redação foi coesa e se baseou nas etapas da síntese para apresentar os diferentes conteúdos do texto.

\section{A realidade da Química Medicinal brasileira}

A redação "A Realidade da Química Medicinal Brasileira" abordou todos os temas que identificamos nos artigos, ou seja, os temas a, b, c e d apresentados no Quadro 1. No primeiro parágrafo [1] apresenta-se uma definição de Química Medicinal, com enfoque na relação estrutura-atividade, e destaque para temas do artigo 2.

[1] "A Química Medicinal é a ciência que detecta compostos com atividades biológicas e, a partir destes, realiza a elucidação da estrutura e caracterização de suas propriedades físico-químicas. Dos fármacos em circulação, apenas pouco mais de $11 \%$ são provenientes de substâncias de origem natural."

O segundo parágrafo [2] aborda diretamente o contexto nacional da síntese de fármacos, ou seja, o tema c, novamente o enfoque se direciona para os produtos naturais, tema do artigo 2 .

[2] "O Brasil, apesar de possuir uma rica flora, não detém tecnologia para desenvolver novos fármacos a partir dela. Opta, assim, por investir em dominar e, consequentemente, aprimorar a produção de medicamentos já consagrados, principalmente, através da síntese orgânica."

No terceiro parágrafo [3] encontramos o tema a, síntese de fármacos, abordada tanto sob o aspecto do artigo 1 quanto do 4 , e novamente o tema c, explorado a partir do artigo 1.

[3] "A produção de fármacos sintéticos envolve altos gastos, especialmente no que se refere à separação de substâncias enantioméricas, levando à comercialização de um alto contingente de misturas racêmicas. Isso ocorre com maior frequência nos países em desenvolvimento, pois suas indústrias farmacêuticas são controladas por multinacionais, as quais visam um lucro imediato, aproveitando-se da baixa legislação deles.”

E no quarto parágrafo [4] encontramos os temas c e d.

[4] "o desenvolvimento tecnológico da indústria farmacêutica brasileira absorveria os profissionais existentes [...] 
empregando-os na descoberta de novo compostos bioativos provenientes de compostos naturais.”

É interessante destacar que, mesmo abordando todos os temas, os alunos tiveram a preocupação de articulá-los ao eixo norteador da redação, exposto no título, "Realidade da Química Medicinal Brasileira". Por isso, em diversos momentos, as questões mercadológicas foram abordadas, sem que fossem as únicas destacadas na redação.

\section{A importância dos fármacos}

A redação "A Importância dos Fármacos" trabalhou os temas a, b e c. No primeiro parágrafo [1] a redação enfoca o tema b, relação estrutura-atividade, e o apresenta como forma de definir a Química Medicinal. Os assuntos abordados nesse parágrafo se assemelham ao artigo 1 .

[1] "Atualmente, uma das principais abordagens para a descoberta e melhoramento de fármacos é a Química Medicinal, que consiste no estudo racional da funcionalidade $e$ estrutura de moléculas com potencial bioativo".

No segundo [2] e terceiro parágrafos [3] a ênfase passa a ser a síntese de fármacos, sendo no segundo parágrafo trabalhada a questão dos produtos naturais, artigo 2 , e no terceiro parágrafo os fármacos sintéticos, artigo 3.

[2] "os primeiros fármacos que vieram a ser utilizados eram provenientes do isolamento e, posteriormente, do isolamento e subsequente modificação de matrizes obtidas a partir de produtos naturais."

[3] "foi possível estudar a relação entre a estrutura da molécula e sua atividade, o que possibilitou o desenvolvimento de técnicas de planejamento racional de fármacos e síntese de estruturas sem uma matriz natural correspondente."

Encontramos no início do quarto parágrafo [4] uma confusão associada à presença de enantiômeros em produtos naturais e sintéticos. As ideias apresentadas pelos alunos estão invertidas, podendo representar um erro de apresentação da informação ou um erro conceitual, que não consideramos prejudicial, pois a tentativa de relacionar os produtos naturais e fármacos sintéticos a partir da quiralidade não apareceu de forma explícita em nenhum artigo, mostrando a originalidade dos autores e uma possível dificuldade em realizar essa inferência. Ainda no quarto parágrafo as questões mercadológicas são brevemente abordadas, remetendo ao tema c e ao artigo 4 que discute a quiralidade.

[4] A grande diferença entre os produtos naturais e os sintéticos é que os primeiros possuem espetacular diversidade de padrões estruturais, que apresentam fonte inesgotável de arquitetura molecular enantio pura de fármacos, enquanto os últimos possuem dois ou mais enantiômeros que podem causar efeitos indesejáveis à saúde do paciente. Por isso, o mercado de fármacos enantiomericamente puros vem crescendo e a indústria farmacêutica vem reformulando a síntese para obtenção de produtos totalmente eficientes.

\section{Química Medicinal desenvolvendo a partir da necessidade}

A redação "Química Medicinal Desenvolvendo a Partir da Necessidade" apresenta os temas a, b e c. O primeiro parágrafo apenas introduz o tema da redação, não permitindo a identificação de nenhum enfoque quanto aos temas descritos no Quadro 1. No início do segundo parágrafo [2] aborda-se o aspecto histórico da síntese de fármacos, presente no artigo 1 dentro do tema a.

[2] "Dessa maneira, a Química Medicinal surgiu no século XIX a partir da necessidade de pesquisas e otimização da síntese de fármacos com ação específica [...] Esta relação foi intensificada com a própria evolução econômica e científica que se deu nessa época."

No restante do segundo parágrafo [2], no terceiro [3] e quarto parágrafos [4] a ênfase é dada na relação entre estrutura e atividade, ou seja, no tema $b$, sendo que os produtos naturais presentes no artigo 2 são discutidos no segundo e terceiro parágrafos, enquanto o quarto parágrafo enfoca o artigo 1 .

[2] "A partir de substâncias isoladas a partir de produtos naturais, percebeu-se a relação entre a estrutura química da molécula e sua ação biológica."

[3] "Num primeiro momento, a descoberta dos fármacos foi baseada no conhecimento milenar da resposta biológica de alguns produtos naturais, o que foi fundamental para a construção do banco de dados de moléculas bioativas...”

[4] "a descoberta de fármacos baseia-se no conhecimento da rota fisiopatológica, ou seja, no conhecimento da atuação de uma determinada molécula na inibição de um processo caótico desencadeador de uma patologia."

No quinto parágrafo [5] observamos novamente alguns aspectos do tema a, como a questão dos produtos sintéticos, presente no artigo 3 e a quiralidade, discutida no artigo 4 .

[5] "a síntese farmacológica que possibilita a produção artificial de produtos bioativos [...] Como fatores importantes para esta síntese, podemos citar a quiralidade, elemento este decisivo tanto na ação farmacológica quanto no custo de produção."

Tanto no último [6] quanto no penúltimo parágrafos [5] observamos menções aos contextos de pesquisa, produção e aspectos mercadológicos associados à síntese de fármacos, o que identificamos como o tema c.

[5] "a síntese farmacológica que possibilita a produção artificial de produtos bioativos, bem como a potencialização deste e sua produção em larga escala"

[6] "evidenciou-se que o desenvolvimento da indústria farmacológica acompanha e incentiva a produção científica humana, sendo os fatores econômicos decisivos tanto para o desenvolvimento das pesquisas quanto para o direcionamento da pesquisa".

\section{AVALIAÇÃO DA PROPOSTA DE ENSINO}

Concluídas as atividades com os artigos de divulgação científica, os estagiários PAE solicitaram aos alunos, por meio da aplicação de um questionário (Quadro 4), que apresentassem suas impressões (21 alunos responderam o questionário). Além disso, os 15 min finais da aula foram reservados para uma discussão geral entre os participantes sobre aspectos da atividade que não haviam sido considerados no referido questionário.

De forma geral, podemos considerar a avaliação dos alunos como 
Quadro 4. Questionário de avaliação da proposta de ensino e respostas dos alunos

(1) Você já trabalhou anteriormente com artigos como recurso didático em alguma disciplina?

$\square \operatorname{Sim}(5-23,8 \%)$;

$\square$ Não $(16-76,2 \%)$.

(2) Depois de ter localizado o seu artigo, como você, a princípio, o consideraria?

$\square$ Interessante, de um modo geral (14 - 66,6\%);

$\square$ Interessante para o seu aprendizado na disciplina de Química Medicina $(7-13,3 \%)$;

$\square$ Desinteressante, de um modo geral;

$\square$ Desinteressante para o seu aprendizado na disciplina de Química

Medicinal;

$\square$ Totalmente desinteressante.

(3) Você teve dificuldade em compreender o conteúdo do artigo?

$\square$ Pouca $(16-76,2 \%)$;

$\square$ Muita $(1-4,7 \%)$;

$\square$ Nenhuma (4-19\%).

(4) Você acredita que a adoção de artigos nas disciplinas de graduação é importante para a sua formação?

$\square$ Pouco importante;

$\square$ Muito importante (21 - 100\%);

$\square$ Não é importante.

(5) Você acredita que esta atividade favoreceu seu aprendizado?

$\square \operatorname{Sim}(19-90,5 \%)$;

$\square$ Sim, porém teria aprendido mais se tivesse trabalhado de outra forma $(2-9,5 \%)$;

$\square$ Não, esta atividade não foi satisfatória para minha aprendizagem.

positiva. Na questão 1 destacamos o fato de que poucos alunos haviam trabalhado com artigos científicos (23,8\%). Quanto à questão sobre os alunos considerarem o artigo interessante ou não, observamos que $100 \%$ dos alunos atribuíram ao artigo qualidades como interessante de um modo geral ou interessante, especificamente, no contexto da disciplina de Química Medicinal.

Diferentemente da ideia que muitos alunos possuem, de que os textos são muito complicados, $80 \%$ dos alunos apresentaram pouca ou nenhuma dificuldade de compreensão do conteúdo do artigo, e justificaram nos questionários que "a dificuldade decorre de termos mais técnicos ou citação de procedimentos específicos, mas nada que represente uma real dificuldade de compreensão".

Com relação à importância da adoção de artigos dessa natureza nas disciplinas, $100 \%$ dos alunos consideraram-na relevante. Destacaram ainda que esta utilização "é importante para podermos aprofundar em assuntos que são tratados superficialmente em aula, ou apenas citados". Os alunos também acreditam que os artigos são "ainda mais [importantes] num curso voltado, em grande parte, à produção científica". Um dos estudantes comentou que "no IME e no ITA os alunos aprendem com teses de doutorado dos professores" e para ele "isso aumenta/melhora o nível das aulas".

De modo geral, todos os alunos acreditam que a atividade favoreceu a aprendizagem, pois permitiu "abstrair o conhecimento teórico (Química) além de permitir a troca de conclusões a respeito dos temas estudados". No entanto, alguns $(9,5 \%)$ alunos não se adaptaram à estratégia empregada, o que é próprio dos processos de ensino e aprendizagem devido às múltiplas diferenças entre os indivíduos.

Os comentários apresentados anteriormente foram escritos na folha do questionário, enquanto surgiram na discussão final outras colocações dos alunos apontando o sucesso da atividade como, por exemplo, a importância e vantagem da troca de experiências e conversa entre os integrantes dos novos grupos, permitindo que tivessem uma visão dos outros artigos sem ter tido o trabalho de ler os outros textos; a possibilidade de conhecer novas substâncias e classes terapêuticas que não tinham sido abordados na disciplina. Os alunos destacaram também que trabalhando dessa forma, "em que o aluno tem que pesquisar, correr atrás do que não sabe, contribui muito para o aprendizado, o conhecimento fica na cabeça, ao contrário de quando estudamos para uma prova", e sugeriram que outros professores solicitassem trabalhos ao longo do semestre ao invés de restringir a avaliação da disciplina às provas.

Como sugestões para uma próxima atividade os alunos apontaram a adoção de seminários, pois acreditam que assim aprenderiam mais. Isso seria realmente interessante, mas não foi aplicado por uma questão de tempo disponível da disciplina, pelo fato da nossa atividade ser extra àquelas previstas pelo professor. Outra sugestão se refere à aplicação da atividade no início da disciplina, quando os alunos ainda não têm tantos compromissos com provas e trabalhos acumulados no final do semestre e podem se dedicar mais à pesquisa. Evitamos este período por acreditar que os alunos não teriam conhecimento suficiente, mas eles argumentaram que iriam justamente atrás desses conhecimentos e assim teriam uma ideia melhor dos conteúdos que seriam abordados na disciplina. Outra sugestão bastante pertinente foi que os artigos fossem mais recentes, uma aluna colocou que "no meu artigo tem dados de 1996, hoje as coisas já mudaram muito"; gostaríamos realmente de ter escolhido artigos mais novos, no entanto por algumas particularidades da Química Medicinal, como o fato de que a maioria dos textos recentes é escrita em inglês, escolhemos estes artigos por relacionarem temas de aspecto geral sobre a Química Medicinal, mesmo trazendo dados não muito atuais. Cabe destacar que a atualização dos dados pode ser solicitada pelo professor aos alunos ou a eles apresentada, concomitantemente ao período de aplicação da proposta.

\section{CONSIDERAÇÕES FINAIS}

Acreditamos que as redações abordaram vários aspectos discutidos nos diferentes artigos, evidenciando uma troca entre os componentes do grupo, que trouxe informações de natureza diversa para o texto. Destacamos que poucos enfocaram a formação de recursos humanos, da mesma forma que essa questão havia sido timidamente discutida nos artigos. Por outro lado, quase todos os textos são sobre a síntese de fármacos e a relação estrutura e atividade, temas de importância fundamental para a Química Medicinal.

Destacamos ainda que todos os grupos trabalharam em conjunto e produziram um texto próprio e coerente do ponto de vista do conteúdo, sendo produções originais resultantes da discussão dos grupos. Desde a escolha dos títulos até a seleção das informações constantes nas redações, percebemos o sucesso da proposta, no sentido de que os alunos tivessem uma melhor noção do que a Química Medicinal estuda e conseguissem relacionar alguns temas de destaque nesta disciplina dentro de um contexto mais geral.

A análise das redações sugere que a atividade alcançou os objetivos de favorecer o ensino e aprendizagem de conteúdos de Química Medicinal, promover uma visão da ciência mais interdisciplinar e próxima da realidade, relacionada com aspectos sociais e econômicos, além de desenvolver habilidades de escrita (uso de terceira pessoa, argumentação apoiada em dados confirmados).

Ademais, a atividade possibilitou a oportunidade de trabalhar conteúdos e desenvolvimento de habilidades dos alunos num formato diferenciado, em relação ao padrão de ensino tradicional ao qual estamos acostumados no ensino superior. Isso nos mostrou que outras formas de trabalho fornecem bons resultados e permitem que os alunos participem da aula de uma maneira mais ativa. 


\section{MATERIAL SUPLEMENTAR}

O texto completo das redações produzidas pelos alunos e analisadas neste artigo encontra-se disponível gratuitamente em http:// quimicanova.sbq.org.br, na forma de arquivo PDF.

\section{AGRADECIMENTOS}

Aos pós-graduandos participantes do programa PAE pela elaboração da proposta de ensino, aos alunos da disciplina SQM0455Química Medicinal do Curso de Ciência Físicas e Biomoleculares e ao professor da disciplina no semestre de aplicação da proposta, C. A. Montanari.

\section{REFERÊNCIAS}

1. Montanari, C. A.; Quim. Nova 1995, 18, 56.

2. Barreiro, E. J.; Quim. Nova 1990, 13, 29.

3. Lima, L. M.; Quim. Nova 2007, 30, 1456.

4. http://cursos.ifsc.usp.br/index-bio-curso.php acessado em Março 2013.

5. Dimmock, J. R.; Am. J. Pharm. Educ. 2000, 64, 44.

6. Roche, V. F.; Alsharif, N. Z.; Am. J. Pharm. Educ. 2002, 66, 319.
7. Herrier, R. N.; Jackson, T. R.; Consroe, P. F.; Am. J. Pharm. Educ. 1997, $61,441$.

8. Carvalho, I.; Pupo, M. T.; Borges, A. D. L.; Bernardes, L. S. C.; Quim. Nova 2003, 26, 428.

9. Andrade, C. H.; Trossini, G. H. G.; Ferreira, E. I.; Revista Eletrônica de Farmácia 2010, 2, 1.

10. Barreiro, E. J.; Manssour, C. A. M.; Química Medicinal: as bases moleculares da ação dos fármacos, Art Med Editora Ltda: Porto Alegre, 2001.

11. Oliveira, J. R. S.; Queiroz, S. L.; Comunicação e Linguagem Científica, Editora Átomo: Campinas, 2007.

12. Barreiro, E. J.; Quim. Nova 1991, 14, 179.

13. Barreiro, E. J.; Quim. Nova 1997, 20, 647.

14. http://www.usp.br/prpg/pt/interna1/pae.html, acessada em Setembro 2012.

15. Teodoro, D. L.; Pagotto, J. F.; Motheo, A. J.; Queiroz, S. L.; Quim. Nova 2011, 34, 714 .

16. Paulson, D. R.; J. Chem. Educ. 2001, 78, 1047.

17. Seetharaman, M.; Musier-Forsyth, K.; J. Chem. Educ. 2003, 80, 1404.

18. Fatareli, E. F.; Ferreira Abreu, L. N.; Ferreira, J. Q.; Queiroz, S. L.; Química Nova na Escola 2010, 32, 161. 


\title{
METODOLOGIA DE ENSINO JIGSAW EM DISCIPLINA DE QUÍMICA MEDICINAL
}

\author{
Luciana Massi, Bianca Machado Cerrutti e Salete Linhares Queiroz*
}

Instituto de Química de São Carlos, Universidade de São Paulo, CP 780, 13560-970 São Carlos - SP, Brasil

\section{Redação “Um Panorama Sobre Química Medicinal”}

\author{
Um Panorama Sobre Química Medicinal
}

A obtenção de um novo fármaco não é um processo trivial. Consiste de uma gama de processos de planejamento e desenvolvimento que acarretam uma considerável demanda de tempo e dinheiro. Neste contexto, está inserida a Química Medicinal, uma ciência que aborda este importante tópico da saúde.

Este processo se inicia com uma gênese planejada de fármacos, na qual estão inseridas as etapas de: programação de pesquisa, que compreende os planejamentos químicos e biológicos, nos quais se incluem os métodos de síntese e avaliação biológica; e a etapa de triagem preliminar, na qual a partir dos compostos obtidos com as pesquisas, é feita uma seleção dos compostos mais promissores que constituem medicamentos em potencial que, então, serão submetidos aos estudos de toxidez, farmacocinética e estudos em animais.

A Química Medicinal trouxe consigo uma diferenciação em todos esses processos na obtenção de fármacos, que a princípio consistia na extração e isolamento de princípios ativos de compostos naturais com atividade biológica popularmente conhecida e posteriormente estudo de seus derivados.

Podemos generalizar a gênese e o desenvolvimento de um fármaco em algumas etapas principais. A começar com o estudo da estrutura molecular que está associada à doença e determinar esta estrutura; então, desenvolve-se a molécula orgânica que vai agir no sítio ativo dessa estrutura, neste tópico é importante citar que muitas destas moléculas orgânicas são enantioméricas, contudo, em algumas delas só um dos compostos enantiômeros é ativo no sistema biológico, enquanto o outro não possui atividade terapêutica, ou às vezes um deles possui uma atividade não desejada dentro do organismo. Por isso são importantes os processos de separação de enantiômeros, para assim, desenvolver fármacos utilizando somente o enantiômero de interesse, sem contar que com um fármaco puro, as pessoas diminuiriam a quantidade de remédio consumida em comparação à uma mistura racêmica dos dois enantiômeros, o que implica, também, em menos gastos na produção do fármaco.

Dando continuidade aos processos, com a molécula pronta, passa-se para os testes in vitro e vencida esta etapa, passam-se aos estudos farmacocinéticos, farmacodinâmicos e de toxidez e, enfim, são realizados os testes in vivo.

Todos esses processos envolvem muitos estudos, e muitos investimentos, que provêm de particulares e por ser este um investimento a longo prazo e de risco, o lucro após o desenvolvimento do fármaco é muito almejado, podendo um remédio chegar a ser dezessete vezes mais caro do que seu custo de produção.

Por todos estes motivos, o desenvolvimento de fármacos é um processo tão complexo e que por isso fica

restrito aos países com melhores condições, que acabam monopolizando este conhecimento.

\section{Redação “A Realidade da Química Medicinal Brasileira"}

\section{A Realidade da Química Medicinal Brasileira}

A Química Medicinal é a ciência que detecta compostos com atividades biológicas e, a partir destes, realiza a elucidação da estrutura e caracterização de suas propriedades físico-químicas. Dos fármacos em circulação, apenas pouco mais de $11 \%$ são provenientes de substâncias de origem natural.

Os vegetais são fonte de inúmeras substâncias bioativas (em muitas das quais, o mecanismo de ação não é totalmente conhecido). O Brasil, apesar de possuir uma rica flora, não detém tecnologia para desenvolver novos fármacos a partir dela. Opta, assim, por investir em dominar e, consequentemente, aprimorar a produção de medicamentos já consagrados, principalmente, através da síntese orgânica.

A produção de fármacos sintéticos envolve altos gastos, especialmente no que se refere à separação de substâncias enantioméricas, levando à comercialização de um alto contingente de misturas racêmicas. Isso ocorre com maior frequência nos países em desenvolvimento, pois suas indústrias farmacêuticas são controladas por multinacionais, as quais visam um lucro imediato, aproveitando-se da baixa legislação deles.

Analisando os fatos citados acima, o desenvolvimento tecnológico da indústria farmacêutica brasileira absorveria os profissionais existentes, que em sua maioria são atraídos pelas elevadas políticas salariais promovidas pelas grandes empresas estrangeiras, empregando-os na descoberta de novo compostos bioativos provenientes de compostos naturais.

\section{Redação "A Importância dos Fármacos"}

\section{A Importância dos Fármacos}

Medicamento é um produto farmacêutico, tecnicamente obtido ou elaborado com finalidade profilática, curativa, paliativa ou para fins de diagnóstico. Atualmente, uma das principais abordagens para a descoberta e melhoramento de fármacos é a Química Medicinal, que consiste no estudo racional da funcionalidade e estrutura de moléculas com potencial bioativo.

A motivação inicial da Química Medicinal foi os produtos naturais - de fato, os primeiros fármacos que vieram a ser utilizados eram provenientes do isolamento e, posteriormente, do isolamento e subsequente modificação de matrizes obtidas a partir de produtos naturais.

Com o avanço das técnicas de caracterização foi possível estudar a relação entre a estrutura da molécula e sua atividade, o que possibilitou o desenvolvimento de técnicas de planejamento racional de fármacos e síntese de estruturas sem uma matriz natural correspondente.

A grande diferença entre os produtos naturais e os sintéticos é que os primeiros possuem espetacular diversidade de padrões estruturais, que apresentam fonte inesgotável de arquitetura molecular enantio pura de fármacos, enquanto os últimos possuem dois ou 
mais enantiômeros que podem causar efeitos indesejáveis à saúde do paciente. Por isso, o mercado de fármacos enantiomericamente puros vem crescendo e a indústria farmacêutica vem reformulando a síntese para obtenção de produtos totalmente eficientes.

\section{Redação “Química Medicinal Desenvolvendo a Partir da Necessidade"}

Química Medicinal Desenvolvendo a Partir da Necessidade

A busca por substâncias com respostas biológicas específicas constituiu a base da Química Medicinal. Assim, o conhecimento dos fitoterápicos foi o ponto de partida para essa evolução.

Dessa maneira, a Química Medicinal surgiu no século XIX a partir da necessidade de pesquisas e otimização da síntese de fármacos com ação específica. A partir de substâncias isoladas de produtos naturais, percebeu-se a relação entre a estrutura química da molécula e sua ação biológica. Esta relação foi intensificada com a própria evolução econômica e científica que se deu nessa época.
Num primeiro momento, a descoberta dos fármacos foi baseada no conhecimento milenar da resposta biológica de alguns produtos naturais, o que foi fundamental para a construção do banco de dados de moléculas bioativas e continua sendo até hoje, daí a importância do estudo desses produtos naturais.

Já no momento presente, a descoberta de fármacos baseia-se no conhecimento da rota fisiopatológica, ou seja, no conhecimento da atuação de uma determinada molécula na inibição de um processo caótico desencadeador de uma patologia.

Permeando a pesquisa científica para o desenvolvimento de fármacos, temos a síntese farmacológica que possibilita a produção artificial de produtos bioativos, bem como a potencialização deste e sua produção em larga escala. Como fatores importantes para esta síntese, podemos citar a quiralidade, elemento este decisivo tanto na ação farmacológica quanto no custo de produção.

Portanto, evidenciou-se que o desenvolvimento da indústria farmacológica acompanha e incentiva a produção científica humana, sendo os fatores econômicos decisivos tanto para o desenvolvimento das pesquisas quanto para o direcionamento da pesquisa. 